\title{
Left ventricular diastolic dysfunction and plasma asymmetric dimethylarginine concentration in persons with essential hypertension
}

\author{
Rafał Poręba ${ }^{1}$, Paweł Gać ${ }^{1}$, Małgorzata Poręba ${ }^{2}$, Arkadiusz Derkacz ${ }^{1}$, Angelika Chachaj ${ }^{1}$, \\ Grzegorz Mazur ${ }^{1}$, Andrzej Szuba ${ }^{1}$
}

${ }^{1}$ Department of Internal Medicine, Occupational Diseases and Hypertension,
Wroclaw Medical University, Wroclaw, Poland
${ }^{2}$ Department of Pathophysiology, Wroclaw Medical University, Wroclaw, Poland

Submitted: 23 February 2013

Accepted: 15 July 2013

Arch Med Sci 2015; 11, 3: 521-529

DOI: 10.5114/aoms.2015.52354

Copyright (c) 2015 Termedia \& Banach

\section{Abstract}

Introduction: The study aimed to evaluate the relationship between plasma asymmetric dimethylarginine (ADMA) concentration and development of left ventricular diastolic dysfunction (LVDD) in patients with essential hypertension (EH). Moreover, an attempt was made to define independent risk factors of LVDD in patients with EH.

Material and methods: A group of 106 individuals with EH was obtained (mean age: $47.18 \pm 11.76$ years). Two groups of patients were distinguished: group I - individuals with EH with LVDD $(n=57)$; group II - persons with EH without LVDD $(n=49)$. Echocardiographic examination was conducted by the transthoracic technique. High-performance liquid chromatography was used to measure dimethylarginine concentrations.

Results: In the group suffering from EH with LVDD, mean ADMA concentration was significantly higher and the ratio of arginine to ADMA was significantly lower than in patients with EH without LVDD. No significant differences were detected between mean concentrations of plasma symmetric dimethylarginine concentration (SDMA) and arginine or in arginine/SDMA ratios in the studied groups. Independent factors of LVDD risk in the study group included higher plasma ADMA concentration, higher serum low-density lipoprotein (LDL) concentration, higher values of body mass index (BMI), higher values of left ventricular mass index (LVMI) and higher values of mean blood pressure $(\mathrm{mBP})\left(\mathrm{OR}_{\mathrm{ADMA}}=1.731 ; \mathrm{OR}_{\mathrm{LDL}}=1.188 ; \mathrm{OR}_{\mathrm{BMI}}=1.056\right.$; $\left.\mathrm{OR}_{\text {LVMI }}=1.062 ; \mathrm{OR}_{\mathrm{mBP}}=1.014 ; p<0.05\right)$.

Conclusions: The results of this study showed that ADMA concentration may be of prognostic value in relation to manifestation of LVDD in patients with $\mathrm{EH}$.

Key words: dimethylarginines, echocardiography, blood pressure.

\section{Introduction}

Untreated essential hypertension results in several complications, related first of all to the heart (hypertrophy of the left ventricle, atrial fibrillation, ischaemic heart disease, acute coronary syndromes, left ventricular diastolic dysfunction, heart failure), blood vessels (dysfunction of endothelium, atherosclerosis, aortal aneurism), central nervous system (haemorrhagic and ischaemic strokes, vascular dementia, retinopathy)

\author{
Corresponding author: \\ Rafał Poręba \\ Department \\ of Internal Medicine, \\ Occupational Diseases \\ and Hypertension \\ Wroclaw Medical University \\ 213 Borowska St \\ 50-556 Wroclaw, Poland \\ Phone: +48 607622534 \\ E-mail: sogood@poczta. \\ onet.pl
}


and kidneys (albuminuria, proteinuria, chronic renal insufficiency) [1, 2].

Left ventricular diastolic dysfunction is thought to represent a relatively early complication of essential hypertension [3, 4]. Echocardiographic verification of left ventricular diastolic dysfunction, even if it seems to be a relatively simple and accessible method, nevertheless allows one to establish the diagnosis when myocardial injury is relatively well advanced [5]. Looking at the epidemiological aspect of the problem and the positive effect of undertaking early treatment on the subsequent prognosis, it seems indispensable to detect early risk factors of developing left ventricular diastolic dysfunction and to look for markers that manifest the strongest possible correlation with development of the pathology in the future.

Our previous pilot study showed the relation between left ventricular diastolic dysfunction and endothelial dysfunction, assessed by flow-mediated vasodilatation [6]. At present, asymmetric dimethylarginine (ADMA) represents a recognised marker of endothelial dysfunction [7-9]. Asymmetric dimethylarginine represents an endogenous, competitive inhibitor of endothelial nitric oxide synthase (eNOS). Asymmetric dimethylarginine is generated as a result of hydrolysis of proteins rich in methylated arginine residues, mainly of histones. Methylation of arginine in proteins is catalysed by the enzyme protein methyltransferase (PRMT). Activity of PRMT type I results in formation of ADMA, while activities of PRMT types II and VII provide symmetric dimethylarginine (SDMA). Symmetric dimethylarginine is unable to inhibit activity of nitrogen oxide synthase [10].

The study aimed to evaluate the relationship between plasma ADMA concentration and development of left ventricular diastolic dysfunction and its echocardiographic types in patients with essential hypertension diagnosed within the last 5 years. Moreover, an attempt was made to define independent risk factors of left ventricular diastolic dysfunction in patients with essential hypertension.

\section{Material and methods}

\section{Studied population}

The study was performed on 147 consecutive patients. The patient inclusion criteria were age between 18 and 65 years old and diagnosis of essential hypertension within the last 5 years. The following exclusion criteria were adopted (in brackets the number of patients excluded due to a specific criterion is given): diagnosed secondary arterial hypertension (14 patients); diagnosed and pharmacologically treated diabetes mellitus (8), ischaemic heart disease (16), hypercholeste- rolaemia (14) and hypertriglyceridaemia (18). The criteria resulted in exclusion of 41 patients. As a result a group of 106 individuals with essential hypertension was obtained, in whom pharmacotherapy was implemented (mean age of patients: $47.18 \pm 11.76$ years). Employing the criterion of left ventricular diastolic dysfunction, two groups of patients were distinguished: group I - individuals with essential hypertension with left ventricular diastolic dysfunction ( $n=57$ ); and group II - persons with essential hypertension without left ventricular diastolic dysfunction $(n=49)$. Clinical characteristics together with characteristics of treatment of essential hypertension are presented in Table I. At the subsequent stage of the study, the criterion of left ventricular diastolic dysfunction permitted us to distinguish 3 subgroups within group I: subgroup IA of patients with essential hypertension with left ventricular diastolic dysfunction of impaired left ventricular relaxation $(n=36)$, subgroup IB of patients with essential hypertension with left ventricular diastolic dysfunction manifesting pseudonormalisation of left ventricular filling $(n=17)$, and subgroup IC of patients with essential hypertension with left ventricular diastolic dysfunction of restrictive filling pattern $(n=4)$.

\section{Basic and asymmetric dimethylarginine measurements}

Written informed consent was obtained from all persons taking part in the study. The study was approved by the Local Ethics Committee. In each of the examined subjects, basic anthropometric data were collected, as well as arterial blood pressure measurements with application of the Korotkov method. Also blood samples were taken to determine serum lipid profile. High-performance liquid chromatography (HPLC) was used to measure plasma arginine, ADMA and SDMA concentrations with ortho-phthalaldehyde for fluorescence determination; it was performed on the system equipped with a fluorescence detector for excitation at $340 \mathrm{~nm}$ and emission at $455 \mathrm{~nm}[11,12]$.

\section{Echocardiography}

Echocardiographic examination was conducted by the transthoracic technique, employing the ProSound Alpha 10 system (Aloka Inc, Tokyo, Japan) using the 3.5/2.7 MHz transducer. The patients were studied with two-dimensional guided M-mode echocardiography in parasternal long axis view, and left ventricular end-diastolic diameter (LVEDD), left ventricular end-systolic diameter (LVESD), inter-ventricular septum end-diastolic diameter (IVSEDD) and posterior wall end-diastolic diameter (PWEDD) were measured, according to 
Table I. Clinical characteristics and characteristics of hypotensive treatment in the study groups (I: group with essential hypertension with left ventricular diastolic dysfunction, II: group with essential hypertension without left ventricular diastolic dysfunction)

\begin{tabular}{|c|c|c|c|}
\hline Parameter & Group I $(n=57)$ & Group II $(n=49)$ & Value of $p$ \\
\hline Age [years] & $46.66 \pm 12.63$ & $47.78 \pm 10.75$ & NS \\
\hline Height $[\mathrm{m}]$ & $1.68 \pm 0.08$ & $1.66 \pm 0.09$ & NS \\
\hline Body mass [kg] & $74.28 \pm 10.50$ & $72.29 \pm 8.99$ & NS \\
\hline $\mathrm{BMI}\left[\mathrm{kg} / \mathrm{m}^{2}\right]$ & $26.39 \pm 3.05$ & $25.97 \pm 2.48$ & NS \\
\hline $\mathrm{BSA}\left[\mathrm{m}^{2}\right]$ & $1.84 \pm 0.16$ & $1.81 \pm 0.15$ & NS \\
\hline \multicolumn{4}{|l|}{ Gender [\%]: } \\
\hline Male & 40.35 & 40.82 & NS \\
\hline Female & 59.65 & 59.18 & NS \\
\hline Duration of essential hypertension [years] & $2.21 \pm 1.49$ & $2.26 \pm 1.42$ & NS \\
\hline \multicolumn{4}{|c|}{ Grades of essential hypertension according to ESH/ESC [\%]: } \\
\hline Mild & 52.63 & 51.02 & NS \\
\hline Moderate & 42.11 & 46.94 & NS \\
\hline Severe & 5.26 & 2.04 & NS \\
\hline Hypotensive treatment [\%]: & 100.00 & 100.00 & NS \\
\hline Monotherapy & 45.61 & 40.82 & NS \\
\hline Combination therapy & 54.39 & 59.18 & NS \\
\hline Hypotensive drugs [\%]: & 100.00 & 100.00 & NS \\
\hline ACE inhibitors & 57.89 & 57.14 & NS \\
\hline$\beta$-blockers & 54.39 & 55.10 & NS \\
\hline Diuretics & 26.32 & 30.61 & NS \\
\hline Calcium channel blockers & 26.32 & 26.53 & NS \\
\hline Angiotensin receptor blockers & 8.77 & 10.20 & NS \\
\hline Other hypotensive drugs & 7.02 & 8.16 & NS \\
\hline Duration of pharmacological treatment [years] & $2.04 \pm 1.36$ & $2.07 \pm 1.33$ & NS \\
\hline
\end{tabular}

ACE - Angiotensin-converting enzyme inhibitors, BMI - body mass index, BSA - body surface area, ESC - European Society of Cardiology, ESH - European Society of Hypertension.

the Penn convention. Measurements of the left atrium (LA) were also taken in parasternal long axis view. In the assessment, mean values of three cardiac cycles were taken. Left ventricular mass (LVM) was determined by means of a formula suggested by the American Society of Echocardiography (ASE) modified by Devereux: LVM $=0.8$ $\times\left(1.04 \times(\text { LVEDD + IVSEDD + PWEDD })^{3}-\right.$ LVEDD $\left.^{3}\right)$ +0.6 (LVEDD, PWEDD and IVSEDD expressed in $\mathrm{cm})$. The left ventricular mass index (LVMI) was determined on the basis of left ventricular mass by dividing the LVM value by body surface area (BSA), expressed in square metres. Body surface area was determined using the Du Bois formula: $\mathrm{BSA}=0.007184 \times(\text { body mass }[\mathrm{kg}])^{0.425} \times$ (height $[\mathrm{cm}])^{0.725}$. Left ventricular ejection fraction (LVEF) was determined from the apical four-chamber and two-chamber views, with the biplane Simpson's method. Parameters of left ventricular diastolic function were determined by pulsed Doppler and tissue Doppler techniques. Using pulsed Doppler technique transmitral flow velocities, including maximal early diastolic mitral flow velocity (E) and maximal late diastolic mitral flow velocity (A), deceleration time of E velocity (DT) and isovolumetric relaxation time (IVRT) were determined, and also E/A ratio. With tissue Doppler imaging early diastolic mitral annular velocities were recorded (E'). Left ventricular diastolic dysfunction was diagnosed when $E / E$ ' $\geq 15$. If $E / E^{\prime}$ results were inconclusive and only suggested left ventricular diastolic dysfunction $\left(8<E / E^{\prime}<15\right)$, estimation of the 
mitral flow velocity profiles and the determination of left atrial volume index (LAVI) and left ventricular mass index (LVMI) were used. Left ventricular diastolic dysfunction was then diagnosed when $\mathrm{E} / \mathrm{A}<0.5$ and, simultaneously, deceleration time (DT) $>280 \mathrm{~ms}$ or when LAVI $>40 \mathrm{ml} / \mathrm{m}^{2}$ or LVMI $>122 \mathrm{~g} / \mathrm{m}^{2}$ in women and $>149 \mathrm{~g} / \mathrm{m}^{2}$ in men [13]. Types of left ventricular diastolic dysfunction were diagnosed using the criteria presented below. Impaired left ventricular relaxation was diagnosed in patients < 50 years when IVRT > 100 ms or DT $>220 \mathrm{~ms}$ or $\mathrm{E} / \mathrm{A}<1$, and in patients $\geq 50$ years old when IVRT > $105 \mathrm{~ms}$ or DT > $280 \mathrm{~ms}$ or $\mathrm{E} / \mathrm{A}<0.8$. Pseudonormalisation of left ventricular filling was diagnosed in patients $<50$ years when DT $=160$ $220 \mathrm{~ms}$ and IVRT $=70-100 \mathrm{~ms}$ and $\mathrm{E} / \mathrm{A}=1.0-1.5$, and in patients $\geq 50$ years old when DT $=160$ $280 \mathrm{~ms}$ and IVRT $=70-105 \mathrm{~ms}$ and $\mathrm{E} / \mathrm{A}=0.8-1.5$. Restrictive filling pattern was diagnosed when DT $<160 \mathrm{~ms}$ and IVRT < $70 \mathrm{~ms}$ and E/A > 1.5 [14].

\section{Statistical analysis}

Statistical analysis was conducted using Statistica 9 software (StatSoft Polska). For quantitative variables arithmetic means $(x)$ and standard deviations (SD) of measured parameters were calculated in the studied groups. Distribution of the variables in the groups was tested using the Lilliefors test and Shapiro-Wilk W-test. In cases of independent quantitative variables with a normal distribution the statistical analysis used the $t$ test for independent variables or one-factor analysis of variance (ANOVA). Homogeneity of variance was tested using tests of Levene and Brown-Forsyth. In cases when variance was non-homogeneous, comparisons of significance of differences between mean values in two groups used the $t$ test with independent estimation of variance while in cases of three or more groups the Kruskal-Wallis ANOVA test was used. In cases of variables man- ifesting a non-normal distribution, for independent quantitative variables the Mann-Whitney $U$ test was used or the non-parametric equivalent of analysis of variance, the Kruskal-Wallis ANOVA test. Significant differences between arithmetic means were estimated using the Newman-Keuls post-hoc test. Results for qualitative variables were expressed in percentages. For independent qualitative variables the subsequent statistical analysis employed the $\chi^{2}$ test. Relationships between studied variables were tested using regression analysis. In cases of quantitative variables with a normal distribution, Pearson's correlation coefficient $r$ was estimated, and in cases of quantitative variables with a non-normal distribution, Spearman's coefficient $r$ was calculated. Parameters of the model obtained in logistic analysis were determined using the quasi-Newton method. Results at the level of $p<0.05$ were assumed to be statistically significant.

\section{Results}

No significant differences in parameters of lipid metabolism, blood pressure or cigarette smoking were observed between the group with essential hypertension with left ventricular diastolic dysfunction and the group with essential hypertension without left ventricular diastolic dysfunction (Table II).

In echocardiographic examination group I demonstrated significantly higher values of LVM and LVMI as compared to those in group II. Studied groups manifested no significant differences in mean values of LVEDD, LVESD, IVSEDD, PWEDD and LA. Simultaneously, no significant differences between the studied groups were found in LVEF. With respect to left ventricular diastolic function, in group I mean values of IVRT and E/E' were statistically significantly higher than in group II, whereas mean values of E/A and E' were signif-

Table II. Parameters of lipid metabolism, arterial blood pressure and characteristics of smoking habit in the study groups (I: group with essential hypertension with left ventricular diastolic dysfunction, II: group with essential hypertension without left ventricular diastolic dysfunction)

\begin{tabular}{|c|c|c|c|}
\hline Parameter & $\begin{array}{l}\text { Group I } \\
(n=57)\end{array}$ & $\begin{array}{l}\text { Group II } \\
(n=49)\end{array}$ & Value of $p$ \\
\hline Systolic blood pressure [mm Hg] & $136.08 \pm 17.46$ & $137.22 \pm 18.89$ & NS \\
\hline Diastolic blood pressure [mm Hg] & $86.79 \pm 8.98$ & $88.90 \pm 10.26$ & NS \\
\hline Cholesterol [mg/dl] & $199.36 \pm 32.60$ & $198.43 \pm 36.82$ & NS \\
\hline LDL $[\mathrm{mg} / \mathrm{dl}]$ & $106.22 \pm 37.81$ & $104.64 \pm 33.19$ & NS \\
\hline $\mathrm{HDL}[\mathrm{mg} / \mathrm{dl}]$ & $52.10 \pm 14.05$ & $53.87 \pm 11.36$ & NS \\
\hline Triglycerides [mg/dl] & $132.77 \pm 65.34$ & $114.14 \pm 64.9$ & NS \\
\hline Smoking habit [\%] & 40.35 & 36.73 & NS \\
\hline Smoking years (number of cigarettes $/ 24 \mathrm{~h} \times$ years of smoking) & $196.16 \pm 103.66$ & $219.16 \pm 82.33$ & NS \\
\hline
\end{tabular}


icantly lower. The studied groups manifested no significant differences between mean values of DT (Table III).

In the group suffering from essential hypertension with left ventricular diastolic dysfunction mean plasma ADMA concentration was significantly higher and the ratio of arginine to ADMA was significantly lower than in patients with essential hypertension without left ventricular diastolic dysfunction. No significant differences were detected between mean concentrations of SDMA and arginine or in arginine/SDMA ratios in studied groups (Table IV). Comparative analysis of mean arginine concentrations and concentrations of its dimethyl derivatives between the subgroups distinguished on the basis of left ventricular diastolic dysfunction demonstrated that in groups of es- sential hypertension with impaired LV relaxation, with pseudonormalisation of LV filling and with restrictive filling pattern, mean plasma ADMA concentrations were significantly higher and the ratio of arginine to ADMA was significantly lower than in patients with essential hypertension without left ventricular diastolic dysfunction. In the group with essential hypertension with restrictive filling pattern mean plasma concentration of ADMA was significantly higher than in patients with essential hypertension with impaired LV relaxation. In the group with essential hypertension with restrictive filling pattern mean plasma concentration of arginine was significantly lower than in patients with essential hypertension without left ventricular diastolic dysfunction. The distinguished subgroups demonstrated no significant differences between

Table III. Echocardiographic parameters in the study groups (I: group with essential hypertension with left ventricular diastolic dysfunction, II: group with essential hypertension without left ventricular diastolic dysfunction)

\begin{tabular}{|lccc|}
\hline Parameter & Group I $(n=57)$ & Group II $(n=49)$ & Value of $p$ \\
\hline LVEDD [mm] & $47.62 \pm 6.67$ & $46.57 \pm 4.81$ & NS \\
\hline LVESD [mm] & $36.06 \pm 6.90$ & $35.70 \pm 6.41$ & NS \\
\hline IVSEDD [mm] & $12.00 \pm 0.98$ & $11.85 \pm 1.01$ & NS \\
\hline PWEDD [mm] & $10.20 \pm 1.05$ & $10.09 \pm 1.07$ & NS \\
\hline LA [mm] & $38.71 \pm 6.08$ & $37.96 \pm 5.95$ & $<0.05$ \\
\hline LVM [g] & $209.98 \pm 48.73$ & $188.37 \pm 31.33$ & $<0.05$ \\
\hline LVMI [g/m²] & $115.87 \pm 33.83$ & $104.89 \pm 19.40$ & NS \\
\hline LVEF [\%] & $65.76 \pm 8.39$ & $66.12 \pm 8.83$ & $<0.05$ \\
\hline E/A & $1.19 \pm 0.30$ & $1.31 \pm 0.27$ & NS \\
\hline DT [ms] & $166.71 \pm 32.05$ & $159.27 \pm 28.59$ & $<0.01$ \\
\hline IVRT [ms] & $99.60 \pm 22.90$ & $85.88 \pm 18.83$ & $<0.01$ \\
\hline E' $[\mathrm{cm} / \mathrm{s}]$ & $10.62 \pm 1.41$ & $11.37 \pm 1.37$ & $<0.01$ \\
\hline E/E' & $9.14 \pm 2.03$ & $7.97 \pm 2.11$ & \\
\hline
\end{tabular}

$D T$ - Deceleration time of E velocity, E/A - maximal early diastolic mitral flow velocity/maximal late diastolic mitral flow velocity, E' - early diastolic mitral annular velocity, E/E' - maximal early diastolic mitral flow velocity/early diastolic mitral annular velocity, IVRT isovolumetric relaxation time, IVSEDD - interventricular septum end-diastolic diameter, LA - left atrium diameter, LVEDD - left ventricular end-diastolic diameter, LVEF - left ventricular ejection fraction, LVESD - left ventricular end-systolic diameter, LVM - left ventricular mass, $L V M I$ - left ventricular mass index, PWEDD - posterior wall end-diastolic diameter.

Table IV. Plasma arginine, ADMA and SDMA concentrations in the study groups (I: group with essential hypertension with left ventricular diastolic dysfunction, II: group with essential hypertension without left ventricular diastolic dysfunction)

\begin{tabular}{|lccc|}
\hline Parameter & Group I $(n=57)$ & Group II $(n=49)$ & Value of $p$ \\
\hline ADMA $[\mu \mathrm{mol} / \mathrm{l}]$ & $0.95 \pm 0.26$ & $0.66 \pm 0.23$ & $<0.001$ \\
\hline SDMA $[\mu \mathrm{mol} / \mathrm{I}]$ & $0.80 \pm 0.48$ & $0.85 \pm 0.47$ & $\mathrm{NS}$ \\
\hline Arginine $[\mu \mathrm{mol} / \mathrm{I}]$ & $22.74 \pm 10.43$ & $25.77 \pm 8.51$ & $\mathrm{~N}$ \\
\hline Arginine/ADMA & $25.90 \pm 15.44$ & $50.17 \pm 37.12$ & $<0.01$ \\
\hline Arginine/SDMA & $40.37 \pm 30.87$ & $66.19 \pm 51.79$ & $\mathrm{NS}$ \\
\hline
\end{tabular}

ADMA - Plasma asymmetric dimethylarginine concentration, SDMA - plasma symmetric dimethylarginine concentration. 
mean concentrations of SDMA or arginine/SDMA ratio (Table V).

In logistic regression analysis conducted in a hierarchical manner taking into account principal anthropological parameters (age, BMI, gender), mean blood pressure (mBP; $\mathrm{mBP}=$ diastolic blood pressure $+1 / 3$ (systolic blood pressure diastolic blood pressure)), LDL cholesterol, LVMI, concentration of arginine and its dimethyl derivatives (ADMA, SDMA) the following model was obtained: logit left ventricular diastolic dysfunction $=-13.701+0.568 \mathrm{ADMA}+0.217 \mathrm{LDL}+0.057 \mathrm{BMI}$ + 0.467 LVMI + $0.198 \mathrm{mBP}$.

Appropriate fitting of the model was confirmed by the value of $\chi^{2}$ statistics, the model's statistical significance $(p<0.01)$ as well as statistical significance found for ADMA $(p<0.01)$, LDL $(p<0.05)$, $\mathrm{BMI}(p<0.05), \operatorname{LVMI}(p<0.05)$ and $\operatorname{mBP}(p<0.05)$. The obtained model demonstrated that independent factors of left ventricular diastolic dysfunction risk in the group with essential hypertension included a higher plasma ADMA concentration, a higher serum LDL concentration, higher values of BMI, higher values of LVMI and higher values of $\mathrm{mBP}\left(\mathrm{OR}_{\mathrm{ADMA}}=1.731 ; \mathrm{OR}_{\mathrm{LDL}}=1.188 ; \mathrm{OR}_{\mathrm{BMI}}=1.056\right.$; $\left.\mathrm{OR}_{\mathrm{LVMI}}=1.062 ; \mathrm{OR}_{\mathrm{mBP}}=1.014 ; p<0.05\right)$ (Table VI).

\section{Discussion}

Endogenous methyl arginines represent products of catabolism in arginine-containing proteins. Arginine residues in proteins undergo methylation under the effect of protein $\mathrm{N}$-methyltransferases (PRMTs) [15]. Various types of protein methyltransferases are known. They differ between each other in their substrate specificity and in products. Action of PRMT I results in formation of ADMA and $\mathrm{N}$-monomethylarginine (MMA). PRMT II and probably also PRMT VII catalyses the formation of symmetric SDMA and MMA [16]. The physiological plasma arginine concentration level is around $50 \mu \mathrm{mol} / \mathrm{l}$ (ranging in various studies between 40 and $84 \mu \mathrm{mol} / \mathrm{l})$, while plasma ADMA concentration is around $1 \mu \mathrm{mol} / \mathrm{l}$ (ranging from 0.4 to $1.3 \mu \mathrm{mol} / \mathrm{l})$, and plasma SDMA concentration is

Table V. Plasma arginine, ADMA and SDMA concentrations in the study subgroups (IA: subgroup with essential hypertension with impaired left ventricular relaxation, IB: subgroup with essential hypertension with pseudonormalisation of left ventricular filling, IC: subgroup with essential hypertension with restrictive filling pattern, II: group with essential hypertension without left ventricular diastolic dysfunction).

\begin{tabular}{|c|c|c|c|c|c|}
\hline Parameter & $\begin{array}{l}\text { Subgroup IA } \\
\quad(n=36)\end{array}$ & $\begin{array}{l}\text { Subgroup IB } \\
\quad(n=17)\end{array}$ & $\begin{array}{c}\text { Subgroup IC } \\
\quad(n=4)\end{array}$ & $\begin{array}{l}\text { Group II } \\
(n=49)\end{array}$ & Value of $p$ \\
\hline ADMA $[\mu \mathrm{mol} / \mathrm{l}]$ & $0.93 \pm 0.23$ & $0.95 \pm 0.25$ & $1.19 \pm 0.46$ & $0.66 \pm 0.23$ & $\begin{array}{l}|\mathrm{A}-| \mathrm{I}: p<0.01 \\
|\mathrm{~B}-| \mathrm{I}: p<0.001 \\
\mid \mathrm{C}-\mathrm{II}: p<0.001 \\
\mid \mathrm{A}-\mathrm{IC}: p<0.05\end{array}$ \\
\hline SDMA $[\mu \mathrm{mol} / \mathrm{I}]$ & $0.81 \pm 0.45$ & $0.82 \pm 0.56$ & $0.78 \pm 0.47$ & $0.85 \pm 0.47$ & NS \\
\hline Arginine $[\mu \mathrm{mol} / \mathrm{l}]$ & $23.01 \pm 10.78$ & $22.19 \pm 9.64$ & $21.89 \pm 6.31$ & $25.77 \pm 8.51$ & $|C-I|: p<0.05$ \\
\hline Arginine/ADMA & $26.06 \pm 17.14$ & $25.77 \pm 8.51$ & $21.22 \pm 3.76$ & $50.17 \pm 37.12$ & $\begin{array}{c}|\mathrm{A}-| \mathrm{I}: p<0.01 \\
|\mathrm{~B}-| \mathrm{I}: p<0.01 \\
|\mathrm{C}-| \mathrm{I}: p<0.001\end{array}$ \\
\hline Arginine/SDMA & $38.19 \pm 26.33$ & $47.81 \pm 40.46$ & $38.28 \pm 17.41$ & $66.19 \pm 51.79$ & NS \\
\hline
\end{tabular}

ADMA - Plasma asymmetric dimethylarginine concentration, SDMA - plasma symmetric dimethylarginine concentration.

Table VI. Results of estimation for the final model obtained in logistic regression analysis

\begin{tabular}{|c|c|c|c|c|c|c|}
\hline \multirow[t]{2}{*}{ Parameter } & \multicolumn{6}{|c|}{ Model for: Probability of left ventricle diastolic dysfunction: P (LVDD) } \\
\hline & Intercept & ADMA & LDL & BMI & LVMI & $\mathrm{mBP}$ \\
\hline Regression coefficient & -13.701 & 0.568 & 0.217 & 0.057 & 0.467 & 0.198 \\
\hline SEM of Rc & 1.094 & 0.024 & 0.018 & 0.009 & 0.021 & 0.017 \\
\hline Value of $p$ & 0.001 & 0.004 & 0.031 & 0.033 & 0.024 & 0.048 \\
\hline Odds ratio (for unit change) & 0.001 & 1.731 & 1.188 & 1.056 & 1.062 & 1.014 \\
\hline \multicolumn{7}{|l|}{ Confidence interval: } \\
\hline$-95 \%$ & 0.001 & 1.614 & 1.090 & 1.027 & 1.024 & 1.007 \\
\hline$+95 \%$ & 0.001 & 1.850 & 1.285 & 1.087 & 1.103 & 1.019 \\
\hline
\end{tabular}

ADMA - Plasma asymmetric dimethylarginine concentration, BMI - body mass index, LVDD - left ventricular diastolic dysfunction, LVMI left ventricular mass index, $m B P$ - mean blood pressure, $P$ - probability, SEM of Rc-standard error of the mean of regression coefficient. 
around $0.7 \mu \mathrm{mol} / \mathrm{l}$ (ranging from 0.5 to $0.8 \mu \mathrm{mol} / \mathrm{l}$ [17-22]. Results obtained in this study for the group of patients with essential hypertension did not differ much from such standard values.

Asymmetric dimethylarginine represents an endogenous inhibitor of endothelial nitric oxide synthase (eNOS) [10]. An increased plasma ADMA concentration leads to impoverished diastolic function of endothelium due to inhibition of eNOS activity. SDMA manifests no ability to inhibit activity of nitrogen oxide synthase [18]. Asymmetric dimethylarginine inhibits in vitro the endothelium-dependent, acetylcholine-induced relaxation of arterial rings [10]. Moreover, it elevates the level of oxidative stress in endothelial cells. First of all, ADMA increases generation of the superoxide anion radical by endothelial cells [23]. The above molecular mechanisms stimulated by the elevated ADMA concentration produce negative alterations in the circulatory system. Therefore, ADMA is considered to represent a significant risk factor for heart diseases [24]. To date, elevated serum concentration of asymmetric dimethylarginine has been detected in several cardiovascular diseases. In patients with atherosclerosis of lower extremity arteries, ADMA concentration correlated with severity of the disease, measured by the distance of intermittent claudication [25]. In the extensive multi-centre CARDIAC (Coronary Artery Risk Determination Investigating the Influence of ADMA Concentration) trials, blood ADMA concentration was proven to grow with the increase in the number of classical risk factors for coronary artery disease. Increase in blood ADMA concentration by $1 \mu \mathrm{mol} / \mathrm{l}$ resulted in a double-fold risk for manifestation of coronary disease [26]. Reports are also available on elevated levels of asymmetric dimethylarginine in heart failure and, even if the precise role of ADMA in pathophysiology of the diseases has not yet been clarified, it is suggested to affect heart rhythm and systolic function of the left ventricle [27]. ADMA is recognised to be an independent risk factor of cardiovascular incidence in patients undergoing percutaneous coronary angioplasty [28]. Moreover, blood ADMA concentration was increased in hypercholesterolaemia [17], hyperhomocysteinaemia $[29,30]$, in children with congenital heart disease and pulmonary hypertension [31] and in patients with dementia in the course of cerebral diseases of vascular origin [32, 33]. Elevated blood ADMA concentration was noted also in persons with arterial hypertension, both adults and children [34, 35]. Vallance et al. in 1992 found that in patients with chronic renal insufficiency arterial hypertension developed significantly more frequently in individuals with elevated blood ADMA concentrations [22].

In such a situation, the relationship between manifestation of essential hypertension compli- cations and plasma ADMA concentration seems interesting. In studies performed so far the relation was poorly recognised. In preliminary investigations the authors of such reports demonstrated that in a randomly selected group of a village population echocardiographic parameters of left ventricular diastolic function correlated with plasma ADMA concentration [36]. In this context, we decided to evaluate the relationship between plasma ADMA concentration and manifestation of left ventricular diastolic dysfunction and its echocardiographic types in patients with essential hypertension diagnosed within the last 5 years. Moreover, we attempted to define independent risk factors of left ventricular diastolic dysfunction development in patients with essential hypertension. Eventually, a defined research group and the control group were selected using criteria listed in the Material and methods. Left ventricular diastolic function was evaluated in line with the current recommendations of cardiological societies, using the suggested method of tissue Doppler imaging. Concentration of endogenous methylarginines was estimated using the generally recognised technique of high-performance liquid chromatography. In our opinion, application of such an approach allowed us to obtain reliable results and to perform an objective analysis.

Analysis of the results obtained in this study confirmed the relationship between plasma ADMA concentration and manifestation of left ventricular diastolic dysfunction in patients with essential hypertension diagnosed within the last 5 years. In the group with essential hypertension with left ventricular diastolic dysfunction, mean plasma ADMA concentration was significantly higher and the ratio of arginine to ADMA was significantly lower than in patients with essential hypertension without left ventricular diastolic dysfunction. On the other hand, no significant differences were observed between mean concentrations of SDMA and arginine and between arginine/SDMA ratios in the studied groups, which seems to exclude a potential relationship between concentrations of the remaining endogenous arginine derivatives and development of left ventricular diastolic dysfunction in patients with essential hypertension diagnosed within the last 5 years. The documented relationships seem to be confirmed by regression analysis. Moreover, the regression analysis allowed us to define independent risk factors of developing left ventricular diastolic dysfunction in the studied group of individuals. The obtained model of logistic regression indicates that the independent risk factors of developing left ventricular diastolic dysfunction in the group of individuals with essential hypertension diagnosed within the last 5 years include higher plasma ADMA con- 
centrations, higher serum LDL concentrations, higher values of body mass index, higher values of left ventricular mass index and higher values of mean blood pressure. Interpretation of odds ratio values showed that in the group of patients with essential hypertension diagnosed within the last 5 years, an increase in plasma ADMA concentrations by $1 \mu \mathrm{mol} / \mathrm{l}$ increases 1.7 -fold the probability of left ventricular diastolic dysfunction. Moreover, this study has demonstrated a relationship between plasma ADMA concentration and manifestation of echocardiographic left ventricular diastolic dysfunction types in the group of patients with essential hypertension diagnosed within the last 5 years. In groups with essential hypertension with impaired LV relaxation, with pseudonormalisation of LV filling and with restrictive filling pattern, mean plasma ADMA concentration was found to be significantly higher and the ratio of arginine to ADMA was significantly lower than in patients with essential hypertension without left ventricular diastolic dysfunction. In the group with essential hypertension with restrictive filling pattern, mean plasma concentration of ADMA was significantly higher than in patients with essential hypertension with impaired LV relaxation. In the group with essential hypertension with restrictive filling pattern, mean plasma concentration of arginine was significantly higher than in patients with essential hypertension without left ventricular diastolic dysfunction. In general, it might be accepted that the left ventricular diastolic dysfunction types with a less favourable prognosis are characterized by higher plasma ADMA concentrations as compared to types of benign left ventricular diastolic dysfunction.

Several limitations of the current study must be acknowledged. Control blood pressure measurements might have been performed using 24-hour ambulatory blood pressure monitoring (ABPM) as it was shown that ABPM better estimates the arterial hypertension-linked risk than classical blood pressure measurements in a doctor's office. Due to the limited number of subjects, the authors decided to include smokers in the study. Exclusion of them would increase the reliability of the study. Finally, the findings of this study need to be replicated in older patients.

In conclusion, the results of this study showed that plasma ADMA concentration may be of prognostic value in relation to manifestation of left ventricular diastolic dysfunction in patients with essential hypertension diagnosed within the last 5 years. It seems possible that in the future plasma ADMA concentration might serve as a diagnostically available marker of left ventricular diastolic dysfunction. For this purpose, however, a simpler technique should be available for estimation of arginine and methylated derivative concentrations. The solution seems to be provided by the immunoenzymatic technique of estimating plasma ADMA concentration suggested by Schulze et al. [37].

In the group of patients with essential hypertension diagnosed within the last 5 years accompanied by left ventricular diastolic dysfunction, significantly higher mean values of plasma ADMA concentration were observed, as compared to the group of patients with essential hypertension diagnosed within the last 5 years without left ventricular diastolic dysfunction. The higher plasma ADMA concentrations, higher serum LDL concentrations, higher values of body mass index, higher values of left ventricular mass index and higher values of mean blood pressure represent independent risk factors of left ventricular diastolic dysfunction in the group of patients with essential hypertension diagnosed within the last 5 years.

\section{Conflict of interest}

The authors declare no conflict of interest.

\section{References}

1. Schmieder RE. End organ damage in hypertension. Dtsch Arztebl Int 2010; 107: 866-73.

2. Banach M, Bhatia V, Feller MA, et al. Relation of baseline systolic blood pressure and long-term outcomes in ambulatory patients with chronic mild to moderate heart failure. Am J Cardiol 2011; 107: 1208-14.

3. Gradman AH, Wilson JT. Hypertension and diastolic heart failure. Curr Cardiol Rep 2009; 11: 422-9.

4. Verma A, Solomon SD. Diastolic dysfunction as a link between hypertension and heart failure. Med Clin North Am 2009; 93: 647-64.

5. Hatle L. How to diagnose diastolic heart failure a consensus statement. Eur Heart J 2007; 28: 2421-3.

6. Szuba A, Poręba R, Pyszel A, Gać P, Derkacz A, Protasiewicz M. Flow mediated dilatation correlates with left ventricle diastolic dysfunction in hypertensive and healthy subjects: preliminary study. Atherosclerosis 2006; Suppl. 7: 220.

7. Landim MB, Casella Filho A, Chagas AC. Asymmetric dimethylarginine (ADMA) and endothelial dysfunction: implications for atherogenesis. Clinics (Sao Paulo) 2009; 64: 471-8.

8. Siekmeier R, Grammer T, März W. Roles of oxidants, nitric oxide, and asymmetric dimethylarginine in endothelial function. J Cardiovasc Pharmacol Ther 2008; 13: 279-97.

9. Barylski M, Małyszko J, Rysz J, Myśliwiec M, Banach M. Lipids, blood pressure, kidney - what was new in 2011? Arch Med Sci 2011; 7: 1055-66.

10. Blackwell S. The biochemistry, measurement and current clinical significance of asymmetric dimethylarginine. Ann Clin Biochem 2010; 47: 17-28.

11. Dobashi Y, Santa T, Nakagomi K, Imai K. An automated analyzer for methylated arginines in rat plasma by high-performance liquid chromatography with post-column fluorescence reaction. Analyst 2002; 127: 54-59.

12. Teerlink T. Determination of the endogenous nitric oxide synthase inhibitor asymmetric dimethylarginine in 
biological samples by HPLC. Methods Mol Med 2005; 108: 263-74.

13. Paulus WJ, Tschöpe C, Sanderson JE, et al. How to diagnose diastolic heart failure: a consensus statement on the diagnosis of heart failure with normal left ventricular ejection fraction by the Heart Failure and Echocardiography Associations of the European Society of Cardiology. Eur Heart J 2007; 28: 2539-50.

14. Zile MR, Brutsaert DL. New concepts in diastolic dysfunction and diastolic heart failure: Part II: causal mechanisms and treatment. Circulation 2002; 105: 1503-8.

15. MacAllister RJ, Parry H, Kimoto $M$, et al. Regulation of nitric oxide synthesis by dimethylarginine dimethylaminohydrolase. Br J Pharmacol 1996; 119: 1533-40.

16. Rho J, Choi S, Seong YR, Cho WK, Kim SH, Im DS. Prmt5, which forms distinct homo-oligomers, is a member of the protein-arginine methyltransferase family. J Biol Chem 2001; 276: 11393-401.

17. Chan JR, Böger RH, Bode-Böger SM, et al. Asymmetric dimethylarginine increases mononuclear cell adhesiveness in hypercholesterolemic humans. Arterioscler Thromb Vasc Biol 2000; 20: 1040-6.

18. Cooke JP. Does ADMA cause endothelial dysfunction. Arterioscler Thromb Vasc Biol 2000; 20: 2032-7.

19. Schmidt RJ, Baylis C. Total nitric oxide production is low in patients with chronic renal disease. Kidney Int 2000; 58: 1261-6.

20. Sydow K, Fortmann SP, Fair JM, et al. Distribution of asymmetric dimethylarginine among 980 healthy, older adults of different ethnicities. Clin Chem 2010; 56: 111-20.

21. Teerlink T, Nijveldt RJ, de Jong S, van Leeuwen PA. Determination of arginine, asymmetric dimethylarginine, and symmetric dimethylarginine in human plasma and other biological samples by high-performance liquid chromatography. Anal Biochem 2002; 303: 131-7.

22. Vallance P, Leone A, Calver A, Collier J, Moncada S. Accumulation of an endogenous inhibitor of nitric oxide synthesis in chronic renal failure. Lancet 1992; 339: 572-5.

23. Böger RH, Bode-Böger SM, Thiele W, Junker W, Alexander K, Frölich JC. Biochemical evidence for impaired nitric oxide synthesis in patients with peripheral arterial occlusive disease. Circulation 1997; 95: 2068-74.

24. Böger RH, Maas R, Schulze F, Schwedhelm E. Asymmetric dimethylarginine (ADMA) as a prospective marker of cardiovascular disease and mortality - an update on patient populations with a wide range of cardiovascular risk. Pharmacol Res 2009; 60: 481-7.

25. Surdacki A. L-arginine analogs-inactive markers or active agents in atherogenesis. Cardiovasc Hematol Agents Med Chem 2008; 6: 302-11.

26. Schulze F, Lenzen $\mathrm{H}$, Hanefeld $\mathrm{C}$, et al. Asymmetric dimethylarginine is an independent risk factor for coronary heart disease: results from the multicenter Coronary Artery Risk Determination investigating the Influence of ADMA Concentration (CARDIAC) study. Am Heart J 2006; 152: 493.e1-8.

27. Saitoh M, Osanai T, Kamada T, et al. High plasma level of asymmetric dimethylarginine in patients with acutely exacerbated congestive heart failure: role in reduction of plasma nitric oxide level. Heart Vessels 2003; 18: 177-82.

28. Frøbert O, Hjortshøj SP, Simonsen U, Ravkilde J. Methylated arginines in stable and acute patients with coronary artery disease before and after percutaneous revascularization. Int J Cardiol 2008; 129: 288-91.

29. Dayal S, Lentz SR. ADMA and hyperhomocysteinemia. Vasc Med 2005; 10: S27-33.
30. Sydow K, Hornig B, Arakawa N, et al. Endothelial dysfunction in patients with peripheral arterial disease and chronic hyperhomocysteinemia: potential role of ADMA. Vasc Med 2004; 9: 93-101.

31. Gorenflo M, Zheng C, Werle E, Fiehn W, Ulmer HE. Plasma levels of asymmetrical dimethyl-L-arginine in patients with congenital heart disease and pulmonary hypertension. J Cardiovasc Pharmacol 2001; 37: 489-92.

32. Khan U, Hassan A, Vallance P, Markus HS. Asymmetric dimethylarginine in cerebral small vessel disease. Stroke 2007; 38: 411-3.

33. Pikula A, Böger RH, Beiser AS, et al. Association of plasma ADMA levels with MRI markers of vascular brain injury: Framingham offspring study. Stroke 2009; 40: 2959-64.

34. Gokce N. L-arginine and hypertension. J Nutr 2004; 134 : 2807S-2811S, 2818S-2819S.

35. Goonasekera CD, Rees DD, Woolard P, Frend A, Shah V, Dillon MJ. Nitric oxide synthase inhibitors and hypertension in children and adolescents. J Hypertens 1997; 15: 901-9.

36. Poręba R, Doroszko A, Chachaj A, et al. Asymmetric dimethylarginine and left ventricle diastolic function. ADMA 2008 - 4th International Symposium on ADMA. Bregenz (Austria), August 28-29, 2008.

37. Schulze F, Wesemann R, Schwedhelm E, et al. Determination of asymmetric dimethylarginine (ADMA) using a novel ELISA assay. Clin Chem Lab Med 2004; 42: 1377-83. 